\title{
Challenges for Conservation: Additional Issues in Developing Strategies and Actions for Conserving Biodiversity
}

\author{
Carlos Frederico D. Rocha ${ }^{1 *}$, Helena G. Bergallo ${ }^{1}$, Elaine C. C. Fidalgo ${ }^{3}$, Maria Alice S. Alves ${ }^{1}$, \\ Marta B. Costa ${ }^{5}$, Monique Van Sluys ${ }^{1}$, Mariella C. Uzêda ${ }^{2}$, Thomaz C. C. Costa ${ }^{4}$, Marcos A. Santos ${ }^{5}$ \\ and Antonio C. R. Cozzolino 5
}

${ }^{1}$ Department of Ecology, Institute of Biology, Universidade do Estado do Rio de Janeiro (UERJ), Rua São Francisco Xavier, 524, Maracanã, 20550-013, Rio de Janeiro, RJ, Brazil

${ }^{2}$ Embrapa Agrobiologia, Rodovia BR465, Km7, Seropédica, 23890-000, RJ, Brazil

${ }^{3}$ Embrapa Solos. Rua Jardim Botânico, 1024, 22460-000, Rio de Janeiro, RJ, Brazil

${ }^{4}$ Embrapa Milho e Sorgo. Rodovia MG 424, km 45, 35701-970, Sete Lagoas, MG, Brazil

${ }^{5}$ CEPERJ - Centro Estadual de Estatísticas Pesquisas e Formação de Servidores Públicos do Rio de Janeiro, Av. Carlos Peixoto, 54, Rio de Janeiro, RJ, Brazil

*Corresponding Author: Carlos F. D. Rocha, Department of Ecology, Institute of Biology, Universidade do Estado do Rio de Janeiro (UERJ), Rua São Francisco Xavier, 524, Maracanã, 20550-013, Rio de Janeiro, RJ, Brazil, Tel: +55 21 2334-0639; E-mail: cfdrocha@gmail.com

Received: 02 September 2017; Accepted: 20 September 2017; Published: 04 October 2017

\section{Conserving Biodiversity}

World Biota and environments are under a high and increasing erosion of biological diversity due to human actions $[1,2]$. That conservation efforts to protect ecosystems and species need to involve the creation of the most possible number of areas as Conservation Units (UCs) is quite obvious. As result, during the last century in different countries some portions of their territories were devoted as UCs. Also, in the last decades, criteria to identify priority areas for conservation have been refined based on the accumulation of knowledge as for example Key biodiversity areas (KBAs) [3, 4], Gap analysis [5, 6] among others, a set of conservation strategies and actions to protect biological diversity. In many cases most of these strategies were predominantly based on the occurrence of remarkable local species richness and occurrence of endemics or threatened species (the most frequently used methodologies usually include almost exclusively aspects related to biodiversity) and consider that the information 
regarding biodiversity is representative for the whole area analyzed. Conversely, in our view, the only recognition of priority areas for conservation per se can fail to be converted in effective protection of biological diversity, because a set of other additional factors besides the simple definition of priority areas for reserves are involved in the designing strategies and actions for conservation for a particular region.

Changing from place to place, from area to area and from region to region means that the status of environmental conservation level also changes along geographical space, as result of a local set of particular factors and historical processes which lead to the present status of conservation of that region or areas. Recognizing such differences along geographical space is crucial in our view to define appropriated set of strategies and actions for that particular region. Here, we describe our experience and approach as an additional way of thinking conservation which focuses on the fact that regions of a political unit differ in socioeconomic and biological aspects, which in turn, would require to be generated specific sets of conservation strategies for each specific region.

Our target was Rio de Janeiro State, Brazil, an area with high biological diversity under extreme human pressure. The economic and social organization of Rio de Janeiro State is presently characterized by a high territorial concentration of the population, of the resources and of the productivity activities delineated along the five centuries process of occupation and development of the state. Considering such marked differences and peculiarities of the occupation/development process of the state, we recognized nine regions of the State [7] which aggregate and share similar characteristics. Also, rather than formulating conservation strategies for Rio de Janeiro State based only on elements of the fauna and flora, the analysis of the current scenario and the routing of proposals must be made based on an integrated and systemic of the biological, economic, social, environmental and political-institutional dimensions. Our approach was based on how defining strategies and actions for conservation is a quite complex process which should involve a large set of aspects, that must be considered together, including biological, sociological, ecological, geomorphological, climatological, hydrological, economical and the actual landscape status among others.

Along three years we gathered georeferenced data on all these aspects, complemented by biodiversity inventories in Forest remnants in the field. The dataset were interrelated showing that the nine regions of the state differed remarkably among them and, generated a different set of strategies to accommodate regional realities.

Data analysis considered the model pressure-state-response [8] (Figure 1) which is based on a concept of causality: human activities exert pressure on the environment, altering its quality and amount of natural resources, i.e. changing consistently its status. The society responds to these changes through environmental, economic or industry (the response of society) (Figures 1 and 2). For each region of the state, the strategy of analysis followed the logic "Given situation A (state), which is subject to pressure $\mathrm{X}$ and associated to the environmental policies $\mathrm{Y}$ (response), which is (are) the action (s) indicated for the conservation of the biodiversity of the Atlantic Rainforest in Rio de Janeiro State?". 


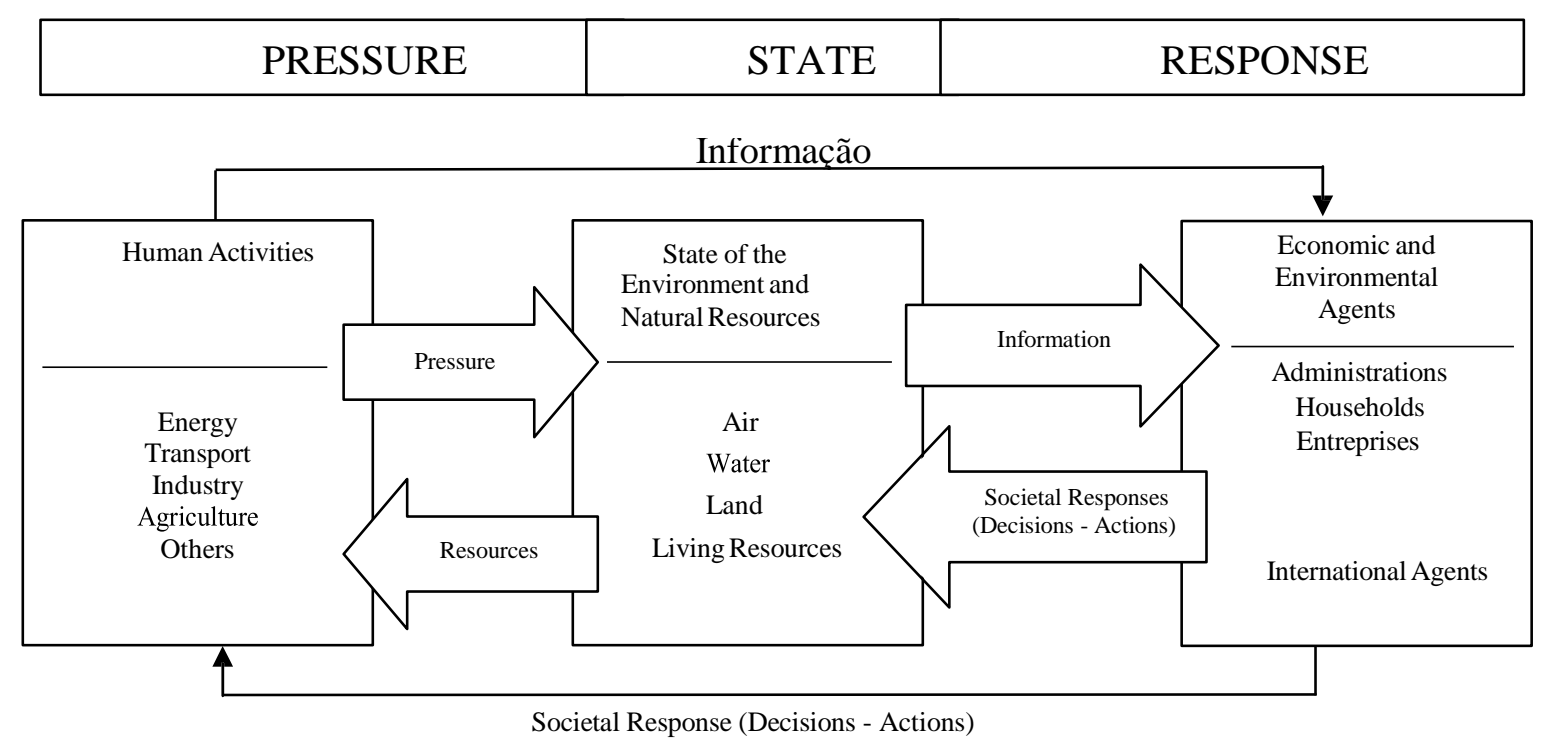

Figure 1: Model pressure-state-response which is based on a concept of causality: human activities exert pressure on the environment, altering its quality and amount of natural resources.

\section{Pressure}

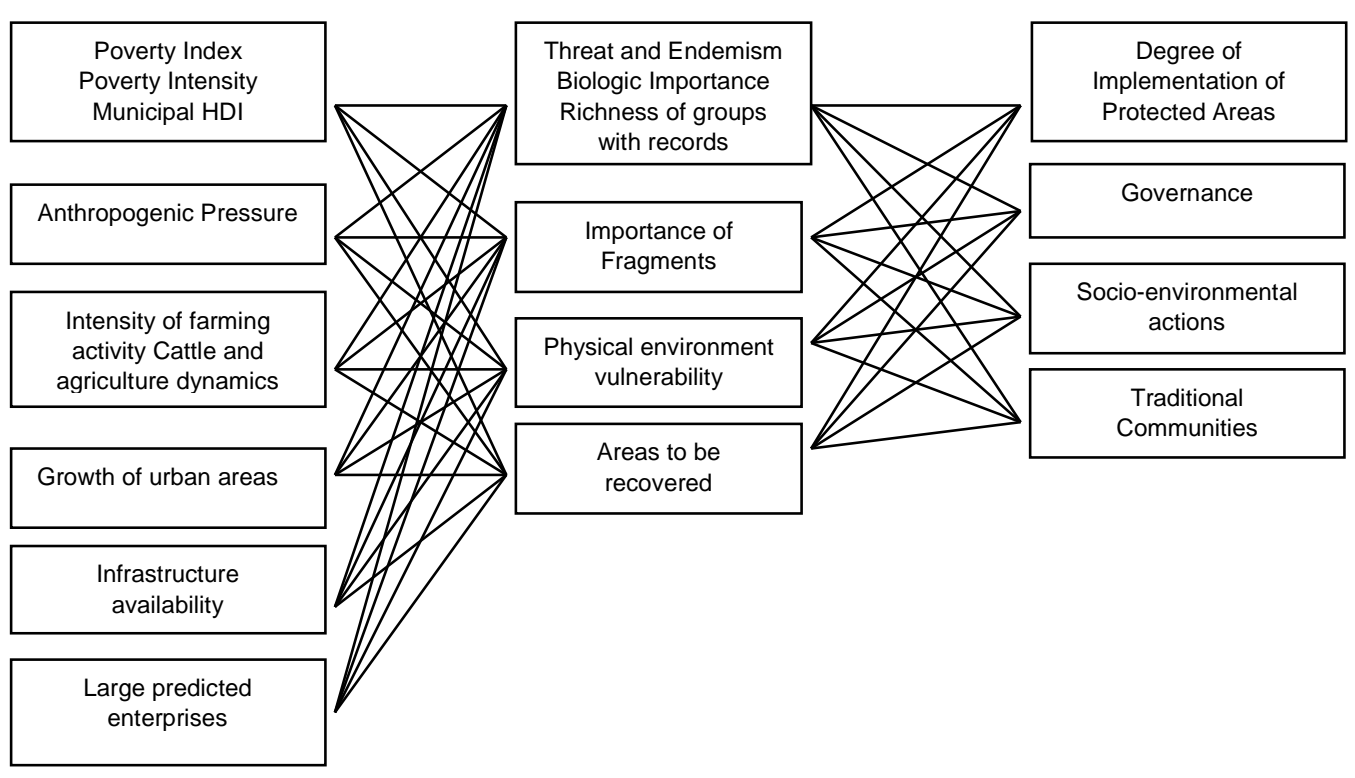

Figure 2: The proposed actions to protect the biodiversity of the Atlantic Rainforest in Rio de Janeiro State was based on the logic pressure-state-response. Hence, given situation A (state), which is subject to pressure $\mathrm{X}$ and associated to the environmental policies Y (response), what actions should be taken?

The strategies and actions for biodiversity conservation in the state were developed and proposed in accordance with the characteristics of each region in order to subsidy with information and proposed actions the policies for conservation, the dissemination of information and the support for planning of the of land use. 
The complete results of our four-year study can be found in the book "Estratégias e ações para a conservação da biodiversidade no Estado do Rio de Janeiro" (Strategies and actions for the conservation of the biodiversity in Rio de Janeiro State) [7].

The proposition of actions was based on strategies aiming the strengthening of the system of Conservation Units, the management of the landscape, the improvement of the quality of life and income generation, the education, the increase of environmental awareness, the involvement of civil society together with the strengthening of local governance, and the increase of existing knowledge on the environment, its processes and the effectiveness of supervision.

With the results obtained in the study, the Project aimed to contribute to the development of policies for conservation, to the dissemination of information, to the support of planning of appropriated land use and to the protection of remnants forests and of the biodiversity of the State of Rio de Janeiro. We believe that the case reported to Rio de Janeiro State is, in general, the same to any portion of any other country because presently most places in the world shares similar set of characteristics involved in conservation challenges.

\section{Acknowledgements}

This study is portion of the results of both the "Programa de Pesquisas em Biodiversidade do Estado do Rio de Janeiro - BIOTA Rio supported by Fundação Carlos Chagas Filho de Amparo à Pesquisa do Estado do Rio de Janeiro - FAPERJ (Process No. E-26_010.001639-2014) to CFD Rocha and of the "Programa de Pesquisas em Biodiversidade da Mata Atlântica (PPBio Mata Atlântica Network)" of Ministério do Meio Ambiente do Brasil (MMA) supported by Conselho Nacional de Desenvolvimento Científico e Tecnológico (CNPq) (Process No. 457458/212-7).The authors benefitted also from grants provided to HGB (process 307781/2014-3) and to CFDR (302974/2015-6 and 472287/2012-5) from CNPq and through "Cientistas do Nosso Estado" Program from FAPERJ to CFDR (process No. E-26/102.765.2012 and E-26/202.920.2015) and to HGB (process E-26/201.267.2014).

\section{References}

1. Moritz C. Strategies to Protect Biological Diversity and the Evolutionary Processes That Sustain It. Systematic Biology 51 (2002): 238-254.

2. Ernst R, Linsenmair KE, Rodel M. Diversity erosion beyond the species level: Dramatic loss of functional diversity after selective logging in two tropical amphibian communities. Biological Conservation 133 (2006): 143-155.

3. Scott JM, Davis F, Csuti B, et al. Gap Analysis: A Geographic Approach to Protection of Biological Diversity. Wildlife Monographs 123 (1993): 3-41.

4. Rodrigues ASL, Akçakaya HR, Andelman SJ, et al. Global Gap Analysis: Priority Regions for Expanding the Global Protected-Area Network. BioScience 54 (2004): 1092-1100. 
5. Jennings MD. Gap analysis: concepts, methods, and recent results. Landscape Ecology 15 (2000): 5-20.

6. Langhammer PF, Bakarr MI, Bennun LA, et al. Identification and Gap Analysis of Key Biodiversity Areas: Targets for Comprehensive Protected Area Systems. IUCN, Gland, Switzerland (2007).

7. Bergallo HG, Fidalgo EC, Rocha CFD, et al. Estratégias e ações para a conservação da biodiversidade no Estado do Rio de Janeiro (1stedn), Instituto Biomas, Rio de Janeiro (2009).

8. Wolfslehner B, Vacik H. Evaluating sustainable forest management strategies with the Analytic Network Process in a Pressure-State-Response framework. Journal of Environmental Management 88 (2008): 1-10.

(C) 1 This article is an open access article distributed under the terms and conditions of the Creative 